\title{
Identification of English Writing Anxiety and Methods to Reduce Stress among Elementary School Students
}

\author{
Dr. Saghir Ahmad Ch., Department of Education, Hazara University Mansehra, Pakistan \\ saghir.edu786@gmail.com \\ *Dr. Ayesha Batool, Assistant Professor, Lahore College for Women University Lahore, Punjab Pakistan \\ drayesharana19@gmail.com \\ Dr. Sadaf Naz, Department of Education, Hazara University Mansehra, Pakistan \\ Anjum Qayyum, Department of Education, Hazara University Mansehra, Pakistan
}

\begin{abstract}
The purpose of the study was identification of English writing anxiety and methods to reduce stress among elementary school students. Anxiety is defined as a feeling of being very worried about something that may happen or may have happened, so that you think about it all the time. The ultimate goal of school is to enable the students to think positively, critically and analyze the problems. The study was descriptive and correlational in nature. The elementary school students of Lahore division were part of the population. However, the total sample of the study was 200 elementary school students. A questionnaire was developed related to English writing anxiety and methods to reduce stress on 5 point likert scale. There were six sub-factors of English writing anxiety for example General worries, Class performance, Teacher stress, Peer pressure, Language difficulties, and Writing pressure. Data were analyzed by applying different statistical techniques. Mostly students were agreed that they feel uncertainty during tests in English and fear about making mistakes in the English. Repeatedly practice and home work may be fruitful to inculcate the foreign language interest among students.
\end{abstract}

Keywords: English, writing, anxiety, stress, elementary students

Received: 25.11 .2020

Published: 13.01 .2021

\section{INTRODUCTION}

The culture of language to be learnt is the most important part of the language learning. The interest in foreign languages and culture has been arisen due to internationalization of business and education (Block, 2007). These factors have made people to see the world and even themselves with new perspectives. With new advancements in the education system around the world, learners should be allowed by teachers to apply their knowledge through creative and critical ideas. They believed that if students want to test their change in thinking and behavior, they should know how to use their prior knowledge and understanding. Both inventive and basic considering ought to be reveled within the learning and educational module through the setting, exercises and questions in school subjects (Canagarajah, 2007).

As per Piaget's cognitive hypothesis, support in creative upgrades the cognition advancement of a child. Included to Piaget's thought, he depicts that children can learn modern things, not as it were by reflecting and creative ability but really on it. Another way of decrease the level of students' stress and anxiety is writing, they reveal their thinking or feelings by words. Writing plays an imperative part for children's early improvements in all spaces like cognitive abilities, dialect, socially, candidly as well as physically. The exercises included for the most open part finished so as to create their considering and analyzing capacities without giving any specific consideration to the item. Taking under consideration the perception, interest, lack of caution and vitality of children, given exercises must be so as to form them think and discover to illuminate issues. Uneasiness has been a concern for numerous a long times in dialect educating and exercised phonetics (Nilsson \& Ferholt, 2014).

Baradaran and Sarfarazi (2011) stated that the concept of achievement in learning English writing is connected with self-expressions, the stream of thoughts, untouchable desires, developing certainty and satisfaction of scholarly writing. They accept that great manuscript includes the capacity to specific thoughts clearly and unquestionably to editor. Moreover, they stretch that creative writing empowers the understudies to precise themselves more effectively and with extraordinary certainty. 
Cheng (2004) discovered learners' composing inconvenience originate from instructive strategy, singular convictions nearly composing and figuring out how to type in, self-discernments, and relational dangers. Cole and Feng (2015) described reasons of writing anxiety to look at 120 language learners in Iran and established that the best three reasons for L2 writing problem were terror of teacher's negative critics, low fearlessness recorded as a hard copy, and phonetic difficulties.

It was discovered that male participants may encounter moderately more noteworthy measure of intellectual tension than female members, particularly in language structure and accentuation. Despite what might be expected, Kirmizi and Kirmiz (2015) explored that male students did not face writing anxiety but they had anxiety in their thoughts. They also determined the significant reasons for composing nervousness were time stress and the critical consideration of the educator. Taking into account the above research discoveries, the analyst chose a nervousness poll ought to remember the seven classifications as referenced for the presentation area of this research.

For students writing inventive English ought to be pleasant. Students ought to have opportunities to select them possess subjects and strategies of writing as the objective of inventive writing is to create children's mental and communication abilities. Besides, sometime recently beginning their writing, students ought to be strengthened to have a thought of each sort of imaginative composing. For outline, in case we conversation almost story composing that numerous students don't have the sense of what story could. Be a sense of what a story is can be strengthened at the starting of the dialog and in case learners are directed in a supportive way in these discussions, they may have started to perceive counterparts and variations between books of writing in foreign language and substance. As a result, they will start to create a thought of the shapes and structures that stories for the most part take after. Before inquiring the students to type in a well portrayed paper or a story it's great in case the educator incorporates a solid discussion in class so that students can share distinctive in course so that students can share distinctive thoughts with the instructor and they can clearly brief the words in their paper. The criticism is additionally an awfully viable procedure to be utilized at the conclusion of the writing session. In the event that the students examined each other's written work and grant feedback that would be steady for the reader and the author as well. But this criticism ought to be observed and modeled by the instructor.

In higher secondary schools it is simple to instruct students' inventive writing but in essential students there are diverse exercises to improve their inventiveness. They are obvious to distinctive sorts of writing exercises which are more organized and planned by their instructors. But it is accepted that these young learners have a tremendous cluster of encounters and information which they have watched around them and so it is claimed that they ought to be designated with parcels of proficiency works. Additionally, as they get an opportunity to play with dialect through creative writing, the more they will play, the more they will learn almost the dialect and the more they learn, the more they will get the certainty to play with dialect. In this way these youthful children will be able to improve their dialect aptitudes.

The issue of causing anxiety is generally seen in Pakistani schools as their moment language isn't commonly English so to manage up with the present day era it is obligatory for the people to memorize English. The issue in Pakistani schools that have been seen is that instructors need in understanding the interface and needs of understudies to enjoy inventiveness in them. It is acknowledged that innovative writing can be wonderful and self-creating in the event that our expressive and open needs convince us for this. In Pakistan, innovative and self-writing is extensively preferred and perceived in schools. There are distinctive sort of classes of creative writing presented in schools such as letter composing, paper composing, creative papers, story composing and exchange composing, these are being practiced in classrooms to upgrade their vocabulary. As indicated by testing issues inside the Pakistani education system of guidance which crash and burn to progress experimental writing in various classes inside the class are the deficiencies inside the instructive projects, assessment, ungainly educators, procedures and strategies. The interest of developing creativity is stressed less but in private schools of Pakistan there are moving towards creativity along with the modern era. They arrange competitions of essay writing to create critical thinking in students. Debates are arranged to develop their confidence (Brown, 2007).

\section{Rationale and Significance of the study}

The main purpose of the study is to explore the anxiety created by English language writing and to search for methods to reduce tension among students. The students of elementary schools were chosen for research because they focus more on learning through 21st century skills. Critical thinking is one of the basic parts of 21st century skills. The ultimate goal of institutes is to enable the students to think critically and analyze the problem so that they not only solve their real life problems but also find solutions for real life problems as well. To promote their confidence and allow them to share their 
thoughts and ideas to express their feelings. It has been seen that students face anxiety during learning English language and writing English. This affects their classroom performance. The ways to reduce anxiety is also given.

This research may be advantageous in numerous ways, because it will not as it were repeat but too uncover the loophole in our educational framework, especially within the school division. Furthermore, it might be critical since it can be used for encourage inquire about in comparable subjects. Thirdly it can be a chunk that can offer assistance educational programs engineers to include such fabric in English based on creating writing aptitudes and to decrease anxiety and pressure whereas writing English. The students feel on edge and pushed to take part in English course and they are scared of making botches. In expansion, they are frightened of their colleagues, joke comments; as a result, they do not take part in English classes and they feel on edge about noteworthiness will advance be measured through its capacity to recognize the imperatives challenge of college students.

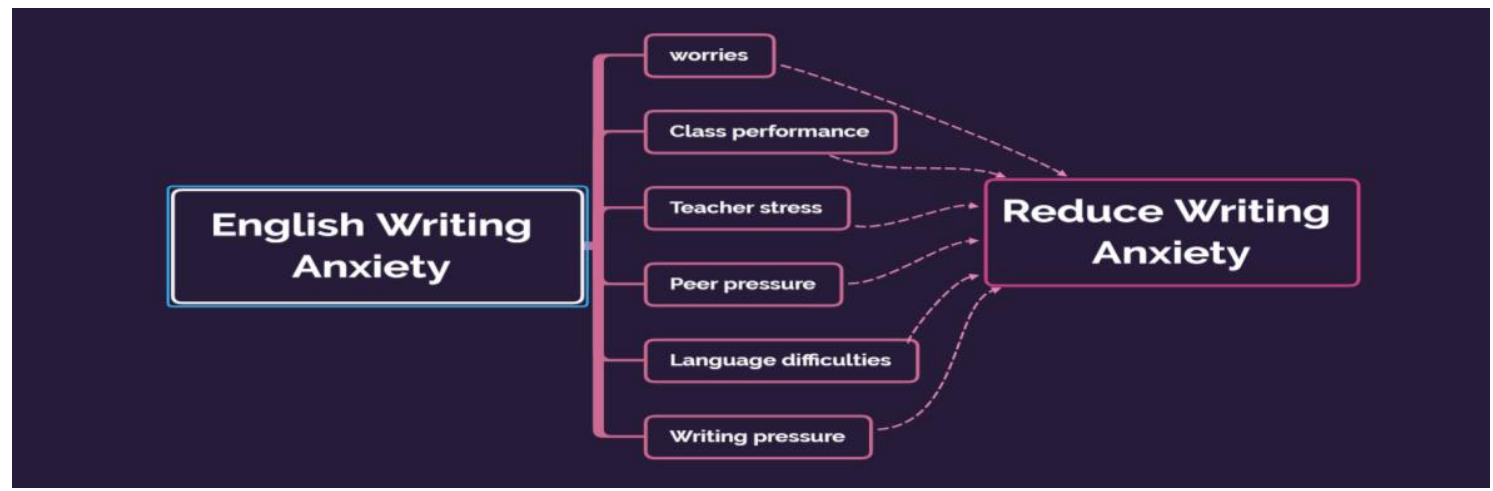

FIGURE 1: English writing anxiety and methods to reduce stress

\section{Research Objectives}

This study was conducted to achieve the following objectives to:

1. Recognize the English writing anxiety among elementary school students.

2. Identify the methods to reduce English writing stress among elementary school students.

3. Observe the correlation between the English writing anxiety and methods to reduce stress among elementary school students.

4. Identify the difference regarding English writing anxiety and methods to reduce stress among elementary school students in terms of demographic variables.

\section{METHODS}

The study was descriptive and correlational in nature. The survey method was used for data collection. The population of the study was elementary school students of Lahore division. Two districts were selected randomly from divisions. Thus, one hundred students were selected from two districts. However, the total sample of the study was 200 elementary school students.

Instrument is the basic ingredient to conduct the study. A questionnaire was developed related to English writing anxiety and methods to reduce stress on 5 point likert scale. There were six sub-factors of English writing anxiety for example General worries, Class performance, Teacher stress, Peer pressure, Language difficulties, and Writing pressure. The second main variable was methods to reduce stress. It was validated by experts and internal consistency was also measured among items by applying Cronbach alpha. There were 37 items in scale and reliability value was .901, which showed high reliable scale. Data were collected by visiting personally. The permission was taken from head teacher of the school and relevant teachers. It was much difficult task to visit personally and collect data. After data collection, different statistics were applied to analyze the data. Mean and standard deviations were calculated in descriptive statistics. To determine the relationship between variables, Pearson $r$ was applied. The inferential statistics were used to check the demographic difference of respondents.

\section{RESULTS and FINDIINGS}

Table 1. Reliability of the Instrument 


\begin{tabular}{cc}
\hline Alpha value & Statements \\
\hline .901 & 37 \\
\hline
\end{tabular}

Table shows the internal consistency of research scale. The questionnaire contained the thirty seven statements about Identification of English Writing Anxiety and Methods to Reduce Stress among School Students. The Cronbach's Alpha was applied to check the reliability of the instrument. There were thirty seven statements and reliability was .901, which is statistical significant.

Table 2. Students worries about English Language

\begin{tabular}{lcc}
\hline General worries & $M$ & $S D$ \\
\hline never quite sure & 3.41 & 1.07 \\
Feel nervousness & 3.64 & .782 \\
Failure fear & 3.79 & .915 \\
Native pressure & 3.84 & .871 \\
Test confusion & 4.24 & .897 \\
Feel confident at home. & 4.11 & .809 \\
\hline
\end{tabular}

Table shows the mean and standard deviation of the replies regarding general worries that most students were agree that they did not feel confidence while writing second language $(M=3.41, S D=$ 1.072), they forget things while writing due to nervousness $(M=3.64, S D=.782)$. They have failure fear due to bad writing means value $(M=3.79, S D=.915)$, they may be nervous due to pressure of native language experts $(M=3.84, S D=.871)$. They confuse in test of foreign language $(M=4.24, S D=.897)$ but they are confident while practicing English at home $(M=4.11, S D=.809)$.

Table 3. Students Performance in English Class

\begin{tabular}{lcc}
\hline Class performance & $M$ & $S D$ \\
\hline Disquiet during tests & 3.86 & 1.09 \\
worry about mistakes & 3.66 & 1.14 \\
Teacher question fear & 4.35 & .720 \\
feel pressure & 4.10 & .675 \\
feel anxious & 4.35 & .489 \\
heart pounding & 4.01 & .698 \\
more tense and nervous & 3.96 & .984 \\
\hline
\end{tabular}

Table shows the mean and standard deviation of the responses about the class performance that most students were agree that they usually disquiet during tests in English $(M=3.86, S D=1.09)$. They worry about mistakes $(M=3.66, S D=1.14)$. They feel anxiety during writing English $(M=4.35, S D=$ .720). They feel compression to prepare the English class $(M=4.10, S D=.675)$. They feel stress even having good preparation $(M=3.35, S D=.489)$. Their heart beat is fast when teacher say to them to translate a single sentence into English $(M=4.01, S D=.698)$ due to this they feel more anxiety and get worried in class $(M=3.96, S D=.984)$.

Table 4. Students Feel Stress in English Class

\begin{tabular}{lcc}
\hline Teacher stress & $M$ & $S D$ \\
\hline Understanding issue & 3.96 & 1.25 \\
tremble on call & 3.73 & 1.01 \\
upset when not understand teacher & 3.95 & .971 \\
afraid while teacher corrects mistake & 4.15 & .768 \\
\hline
\end{tabular}

Table shows that mostly students agree that they get nervous when they are unable to understand the teacher in English class $(M=3.96, S D=1.254)$. They tremble when there are called by the teacher to ask about language $(M=3.73, S D=1.011)$. They get afraid when writing teacher wants to correct mistake $(M=4.15, S D=.768)$.

Identification of English Writing Anxiety and Methods to Reduce Stress among 
Table 5. Students Feel Pressure in English Class

\begin{tabular}{lcc}
\hline Peer pressure & $M$ & $S D$ \\
\hline Students laugh & 4.16 & 1.01 \\
Feel others are better & 4.28 & .513 \\
Others write better & 4.33 & .533 \\
Self-conscious & 4.34 & .51 \\
\hline
\end{tabular}

Table shows students feel peer pressure. Mostly students agree that they are afraid about other students will laugh English writing $(M=4.16, S D=1.015)$. They think other fellows are genius $(M=4.28$, $S D=.513)$. They consider others writing is good $(M=4.33, S D=.533)$. They feel self-conscious about notes and papers being read by other students $(M=4.34, S D=.515)$.

Table 6. Students Feel Difficulties in English Language

\begin{tabular}{lcc}
\hline Language difficulties & $M$ & $S D$ \\
\hline Panic & 4.33 & .665 \\
Feel overwhelmed & 4.33 & .512 \\
Feel embarrassment & 4.52 & .593 \\
Confused without any concept & 4.61 & .564 \\
\hline
\end{tabular}

Table shows the responses about the language difficulties that most of students agree that they feel panic due to language mistakes $(M=4.33, S D=.665)$. They feel incredulous because they are confused when they forget language rules while writing $(M=4.33, S D=.512)$. They are also poor in tenses and sentence structure and this thing is caused of discomfits $(M=4.52, S D=.593)$. They get nervous and confuse because they have no practice or self-confidence to write in English $(M=4.61, S D=.564)$.

Table 7. Students Feel Stress during Writing English

\begin{tabular}{lcc}
\hline Writing stress & $M$ & $S D$ \\
\hline Grammatical errors & 4.21 & .842 \\
wrongly using words & 4.22 & .798 \\
Wrong style and structure. & 4.42 & .759 \\
insufficient time & 3.94 & .774 \\
no idea what to write & 4.06 & .777 \\
Grades & 3.66 & 1.241 \\
\hline
\end{tabular}

Table shows the responses about the writing stress shows that most students agree that they worry about making grammatical blunders $(M=4.21, S D=.842)$. They have concern about use of words at right place $(M=4.22, S D=.798)$. They fear about wrong style and structure $(M=4.42, S D=.759)$. They feel stress because they have less writing ideas $(M=4.06, S D=.777)$ and feel fear about poor grades in exam $(M=3.66, S D=1.241)$.

Table 8. Methods to Reduce Writing Anxiety in English

\begin{tabular}{lcc}
\hline Reduce Writing anxiety & $M$ & $S D$ \\
\hline Grammar & 4.03 & .882 \\
vocabulary and wording & 4.01 & .770 \\
Sentence style and construction & 3.90 & .891 \\
teacher suggestions & 4.22 & .522 \\
Grading & 4.26 & .753 \\
Exam & 4.42 & .725 \\
\hline
\end{tabular}

Table shows of the responses about the writing stress. Mostly students agree that If grammar is not graded their tension in English writing can be reduced $(M=4.03, S D=.882)$. Grading on vocabulary is also influenced the writing stress. Teachers' suggestions are helpful to reduce the stress level in writing of foreign language $(M=4.22, S D=.522)$. They said they had grading fear and this thing is major cause of 
anxiety $(M=4.26, S D=.753)$, it can be reduced to reduce the importance and preference of grading system and exam fear $(M=4.42, S D=.752)$.

Table 9. Correlation between English Anxiety and Reduce Writing Stress

\begin{tabular}{lccccccc}
\hline Factors & 1 & 2 & 3 & 4 & 5 & 6 & 7 \\
\hline General worries & 1 & $.331^{* *}$ & $.563^{* *}$ & $.309^{* *}$ & $.617^{* *}$ & $.383^{* *}$ & $.393^{* *}$ \\
Class performance & & 1 & $.475^{* *}$ & $.526^{* *}$ & $.445^{* *}$ & .026 & $.489^{* *}$ \\
Teacher stress & & & 1 & $.690^{* *}$ & $.601^{* *}$ & $.592^{* *}$ & $.475^{* *}$ \\
Peer pressure & & & & 1 & $.443^{* *}$ & $.350^{* *}$ & $.261^{* *}$ \\
Language difficulties & & & & & 1 & $.410^{* *}$ & $.379^{* *}$ \\
Writing pressure & & & & & & 1 & $.581^{* *}$ \\
Reduce Writing anxiety & & & & & & 1 \\
\hline
\end{tabular}

Table shows the association among general worries with the class performance, teacher stress, peer pressure, language difficulties, writing pressure and reduce writing anxiety. The $r$ - value shows that there was a significant correlation between General worries and Class performance $r=.33$, class performance and teacher stress $r=.475$, Teacher stress and Peer pressure $r=.690$, Peer pressure and Language difficulties $r=.443$, Language difficulties and Writing pressure $r=.410$, and writing pressure and reduce writing anxiety $r=.581$ at $p=.001$. However, it is concluded that there was a strong significant association among factors and between language stresses and reduce writing anxiety.

Table 10. Gender Difference regarding English Anxiety and Reduce Writing Stress

\begin{tabular}{llcccccc}
\hline Factors & Gender & $N$ & Mean & $S D$ & $T$ & $d f$ & Sig. \\
\hline General worries & Male & 59 & 23.73 & 3.722 & 1.521 & 198 & .13 \\
& female & 141 & 22.76 & 4.264 & & & \\
Class performance & Male & 59 & 28.05 & 3.734 & -.654 & 198 & .51 \\
& female & 141 & 28.39 & 3.173 & & & \\
Teacher stress & Male & 59 & 15.97 & 3.742 & .454 & 198 & .65 \\
& female & 141 & 15.72 & 3.317 & & & \\
Peer pressure & Male & 59 & 17.03 & 1.650 & -.455 & 198 & .65 \\
& female & 141 & 17.15 & 1.621 & & & .24 \\
Language & Male & 59 & 17.97 & 1.286 & 1.170 & 198 & .24 \\
difficulties & female & 141 & 17.72 & 1.358 & & & .04 \\
Writing pressure & Male & 59 & 25.10 & 2.440 & 2.029 & 198 & .05 \\
Reduce & female & 141 & 24.28 & 2.694 & & & \\
anxiety & Male & 59 & 25.56 & 2.830 & 2.070 & 198 & \\
\hline
\end{tabular}

Table shows that an independent sample t-test was applied to compare the General worries with the class performance, teacher stress, peer pressure, language difficulties, writing pressure and reduce writing anxiety scores for males and females difference. There was no significant gender difference in general worries, class performance, teacher stress, peer pressure, language difficulties scores. There was significant variance in views of male and female students about writing pressure and reduce writing anxiety scores at $\mathrm{p}=.001$.

Table 11. Class Difference regarding English Anxiety and Reduce Writing Stress

\begin{tabular}{lccccc}
\hline Factors & Sum of Squares & $d f$ & Mean Square & $F$ & Sig. \\
\hline General worries & 412.095 & 3 & 137.365 & 9.045 & .00 \\
& 2976.500 & 196 & 15.186 & & \\
Class performance & 3388.595 & 199 & & & \\
& 12.020 & 3 & 4.007 & .355 & .78 \\
Teacher stress & 2211.160 & 196 & 11.281 & & \\
& 2223.180 & 199 & & & \\
& 94.455 & 3 & 31.485 & 2.730 & .04 \\
\hline
\end{tabular}




\begin{tabular}{lccccc} 
& 2354.595 & 199 & & & \\
Peer pressure & 10.295 & 3 & 3.432 & 1.303 & .27 \\
& 516.060 & 196 & 2.633 & & \\
Language difficulties & 526.355 & 199 & & & .19 \\
& 8.415 & 3 & 2.805 & 1.579 & \\
Writing pressure & 348.180 & 196 & 1.776 & & \\
& 356.595 & 199 & & & \\
Reduce Writing anxiety & 134.640 & 3 & 44.880 & 7.008 & .00 \\
& 1255.280 & 196 & 6.404 & & \\
& 1389.920 & 199 & & & \\
& 153.255 & 3 & 51.085 & 5.214 & .00 \\
\hline
\end{tabular}

Table indicates that One-way ANOVA was applied to know the difference in mean scores of general worries, class performance, teacher stress, peer pressure, language difficulties, writing pressure and reduce writing anxiety on the basis of their classes. Result displays that there was significant difference in mean scores of general worries, teacher stress, writing pressure and anxiety on the basis of class difference at $p=.001$. There was no difference in mean scores of Class performance, peer pressure, and language difficulties.

\section{DísCUSSION and CONCLUSION}

The motive of the study was to recognize the English writing concern and methods to reduce stress among elementary school students. The core objective was to explore the correlation between English writing anxiety and methods to reduce stress among elementary school students. This study was descriptive and correlational in nature. The survey method was used for data collection. The population of the study was elementary school students. The Cronbach's Alpha was applied to check the reliability of the instrument. There were thirty seven statements and reliability was .901, which is statistical significant. Mostly students were agreed that they usually at unease during tests in English and worry about making mistakes in the English. They get nervous when the teacher asks them to write in English what they had not prepared in advance. They feel pressure to prepare very well for the English class, even if they are well prepared for the English, they feel anxious about it. They feel more tense and nervous in English writing.

It is concluded that majority of the students were agreed that they do not understand every word the English teacher says. They get upset when they are unable to understand what the English teacher is saying and they afraid that writing teacher is ready to correct their mistakes. They feel peer pressure that they were afraid that the other students will laugh at English writing. It is also confirmed that they feel that the other students write better English than them and they feel very self-conscious about notes and papers being read by other students. It is concluded that during writing if the teacher does not grade on vocabulary and wording, then their tension in English writing may be overcome. If the educator gives recommendations on writing, their fear in language writing may be condensed. Moreover, it is concluded that there was a strong relationship between class performance and teacher stress. Furthermore, it is concluded that there was a strong relationship between peer pressure and language difficulties. Besides, it is concluded that there was a strong relationship between language difficulties and writing pressure. Moreover, it is concluded that there was a strong relationship between writing pressure and reduce writing anxiety. These findings are following the sayings of Herwitt and Stephenson (2012). Nervousness of class and test is experienced because of learners' pressure that they perform ineffectually in the midst of an assessment or that they miss the mark any edge of a test. It is the most widely recognized outcome that the quality performance of students is less fortunate and they get more lamentable evaluations than others. Dread of negative social evaluation is instigated by learners' anxiety that another person would survey their performance, that appraisal would be contrary or that another individual would outline a pessimistic supposition nearly them. Subsequently, they also go to evade conduct which is to keep away from occasions in which any sort of judgment may appear. The results of the study are also supporting Tran (2012) who studied that English language developed stress among students. 


\section{Recommendations}

This study was about identification of English writing anxiety and methods to reduce stress among elementary school students. Findings showed that students had anxiety to write in English and they tried to overcome in different ways. The first thing is that students are lack of confidence, teachers and parents should develop confidence and motivate those regarding English. It can be overcome learning difficulties and get rid of nervousness of forgetters. Students are confused when they attempt tests in English. So, confusion might be eliminated by building confidence in classroom and home. Teachers and parents should focus on practice and they need to force students to practice the foreign language while writing the things again and again. Repeatedly practice and home work may be fruitful to inculcate the foreign language interest among students. There is a dire need to build interest among learners because they take this as a burden and rote many things like grammar and vocabulary due this they forget these in exams and this thing affect their performance. Students do not care of others and mistakes. They should be stress free and feel positive while writing English.

\section{REFERENCES}

1. Baradaran, A., \& Sarfarazi, B. (2011). The impact of scaffolding on the Iranian EFL learners' English academic writing. Australian Journal of Basic \& Applied Sciences, 5(12), 2265-2273.

2. Block, D. (2007). Second language identities. London: Continuum.

3. Brown, H. D. (2007). Principles of language learning and teaching (5th ed.). White Plains, NY: Pearson Education.

4. Canagarajah, A. S. (2007). Lingua franca English, multilingual communities, and language acquisition. Modern Language Journal, 91(5), 923-939. doi:10.1111/j.1540-4781.2007.00678.x

5. Canagarajah, S. (2011). Multilingual writers and the academic community: Towards a critical relationship. Journal of English for Academic Purposes, 1(1), 29-44. doi:10.1016/S1475-1585(02)00007-3

6. Chen, M. C., \& Lin, H. J. (2009). Self-efficacy, foreign language anxiety as predictors of academic performance among professional program students in a general English proficiency writing test. Perceptual and Motor Skills, 109(2), 420-430. doi:10.2466/PMS.109.2.420-43

7. Cheng, Y. S. (2004). A measure of second language writing anxiety: Scale development and preliminary validation. Journal of Second Language Writing, 13(4), 313-335. doi:10.1016/j.jslw.2004.07.001

8. Cole, J., \& Feng, J. (2015). Effective strategies for improving writing skills of Elementary English Language Learners. Online Submission. Paper presented at the Chinese American Educational Research and Development Association Annual Conference

9. Horwitz, E. K. (2001). Language anxiety and achievement. Annual Review of Applied Linguistics, 21(1), 112-126. doi:10.1017/S0267190501210083

10. Hewitt, E., \& Stephenson, J. (2012). Foreign language anxiety and oral exam performance: A replication of Phillips's MLJ study. The Modern Language Journal, 96(2), 170-189.

11. Kirmizi, O., \& Kirmizi, G. D. (2015). An investigation of L2 learners' writing self-efficacy, writing anxiety and its causes at higher education in Turkey. International Journal of Higher Education, 4(2), 57-66.

12. Nilsson, M., \& Ferholt, B. (2014). Vygotsky's theories of play, imagination and creativity in current practice: Gunilla Lindqvist's “creative pedagogy of play” in US kindergartens and Swedish Reggio-Emilia inspired preschools. Perspectiva, 32(3), 919-950.

13. Tran, T. T. T. (2012). A review of Horwitz, Horwitz and cope's theory of foreign language anxiety and the challenges to the theory. English Language Teaching, 5(1), 69-75. 